\title{
A new technological approach to the granulation of slag melts of ferrous metallurgy: obtaining glassy fine-grained granules of improved quality
}

\author{
David Sakhvadze ${ }^{1}$, Gigo Jandieri ${ }^{2^{*}}$ (D) Giorgi Jangveladze ${ }^{3}$ and Giorgi Sakhvadze ${ }^{4}$
}

\section{* Correspondence: gigo.jandieri@ gmail.com \\ ${ }^{2}$ Metallurgical Engineering and Consulting Ltd., Tbilisi, Georgia Full list of author information is available at the end of the article}

\begin{abstract}
The technological factors required to improve the operational properties of granulated metallurgical slags demanded in the building industry have been analyzed. In order to satisfy these factors, a new technology for hydro-vacuum granulation of slag melts (HVG) has been developed. It is shown that the main advantage of the proposed HVG process is the provision of forced high-speed vortex convection of water, with the effect of vertical suction, crushing, and degassing of the three-phase (water-slag granules-water vapor) heterogeneous medium formed during the overcooling and solidification of slag. It is proved that the high-speed volumetric disintegration and overcooling with the degassing effect sharply reduces a degree of aggressive gas/vapor impact on the being cooled particles of slag, which, in turn, leads to the reduction of the perforation degree of the granules. The obtained granules are distinguished by stable fractionation and improved, welldefined dense amorphous glassy structure, the water-holding capacity of which has reduced from $45-50 \%$ to $25-13 \%$, the actual moisture content from $24-20 \%$ to 6$4 \%$, while the hydraulic activity in terms of CaO-uptake increased from the conventional 320-360 mg/g to 610-650 mg/g. Pilot scale research demonstrated that the designed equipment for the HVG technology allows sustainable control of the quality of granules, and it has the potential for further development and implementation.
\end{abstract}

Keywords: Slag melt, Hydro-vacuum granulation, Overcooling, Degassing, Amorphization, Extraction of metal and graphite inclusions

\section{Introduction}

In connection with inevitable depletion of metal-bearing mineral resources, increased expenses on mining and beneficiation, and the continuous growth of mitigation costs for rehabilitation and reclamation of disturbed lands, the modern mining and metallurgical complexes will be increasingly forced to adapt to such new realities of their functioning as a necessity for strict minimization of production losses and intensification of

(c) The Author(s). 2021 Open Access This article is licensed under a Creative Commons Attribution 4.0 International License, which permits use, sharing, adaptation, distribution and reproduction in any medium or format, as long as you give appropriate credit to the original author(s) and the source, provide a link to the Creative Commons licence, and indicate if changes were made. The images or other third party material in this article are included in the article's Creative Commons licence, unless indicated otherwise in a credit line to the material. If material is not included in the article's Creative Commons licence and your intended use is not permitted by statutory regulation or exceeds the permitted use, you will need to obtain permission directly from the copyright holder. To view a copy of this licence, visit http://creativecommons.org/licenses/by/4.0/. The Creative Commons Public Domain Dedication waiver (http://creativecommons.org/publicdomain/zero/1.0/) applies to the data made available in this article, unless otherwise stated in a credit line to the data. 
treatment processes of accumulating industrial waste with the aim of their highest possible valorization [1-4].

Among the wastes of the metallurgical production of ore-reduction profile (blast furnace and electrocarbothermic production of pig iron and ferroalloys), slag melts generated as by-products during metal/alloy smelting rank first by their scale and ecological hazard. In many cases, the amount of slag generated significantly exceeds the volume of metal produced. Material costs for their evacuation and preparation for subsequent processing increases the cost price of basic products, which reduces profitability and worsens the overall competitiveness of the industrial enterprise. A partial compensation of the above problems is possible by the local, in-plant mastering of the heat and power resource potential of these slag melts. The most efficient way of mastering the thermophysical energy of slags is its utilization for heating water and vapor generation [5] or, in some cases, for sintering (agglomeration) of fine-grained metallic charge [6]. In its turn, the use of these slag melts in the granulated form in the manufacture of building, ceramic, and sorption materials is another rational way for mastering their more valuable mineral-resource potential [7-13]. During granulation, due to rapid cooling (quenching), the slag solidifies in a glassy (amorphous) state and the latent heat of crystallization $(300-400 \mathrm{~kJ} / \mathrm{kg})$ is not released and is realized in the form of chemical energy, giving the slag a valuable quality - hydraulic activity. Valorization of slag melts of metallurgical production by way of granulation will, in addition to extra financial gain, lead to an essential reduction of exploitation and ecological costs on long-term storage of these slags [14].

Among numerous methods of granulation of slag melts, the most progressive and cost-effective are considered the technologies wet granulation from VNIIMT (Scientific-Research Institute of Metallurgical Heat Engineering, Russia) and Paul Wurth technologies - INBA process (SMS Group, Luxemburg) $[15,16]$. According to research $[17,18]$, these technologies are economical by $15-30 \%$ in comparison with such methods as the channel-pool, hydro-channel, or drum granulation. In the first turn, this is conditioned by a reduction of the fleet of slag cars and the number of the operative personnel, as well as the efficiency of processing of molten slags (loses on ladle sculls are reduced). A particular feature of the VNIIMT and Paul Wurth technology is also their environmental friendliness, minimized emission of particularly noxious gases $\mathrm{H}_{2} \mathrm{~S}$ и $\mathrm{SO}_{2}$ and reduced consumption of the used process water. The main disadvantage of wet granulation technologies is a high degree of structural and granulometric heterogeneity of the obtained granules, as well as a high degree of swelling and perforation, which as a result leads to a significant reduction in their quality.

Lately, some country has started to investigate and develop experimental technologies of dry granulation of molten slags with the use of centrifugal units, by analogy with the technology of powder formation from iron melts [19-21]. The system of dry, drum-ball granulation of slag with the possibility of heat recovery is also being piloted [22]. However, based on a critical analysis of the published research, it can be noted that the major shortcoming of these technologies will be reduced productivity, high intensity of failures, and high price of repair. The main advantage of the method of dry granulation of liquid slag melts is a possibility of producing granules with a denser and stronger structure. But, due to a reduction in speed and depth of slag melt overcooling (quenching), a content of particular importance for manufacture of building materials, 
amorphous, hydraulically active glassy phase (HAGP), is reduced in the obtained granulate. This essentially reduces the granulate quality, since it leads to a necessity of its artificial activation [23].

According to the European standard BS EN 15167-1: 2006 and studies [24, 25], the main criteria of granulated slag quality evaluation are the actual content of glassy amorphous phase, which must be at least $66.6 \%$ and a specific surface area $3750-4500$ $\mathrm{cm}^{2} / \mathrm{g}$, obtainable after milling. To achieve this indicator, the granulated slag is subjected to mechanical milling, predominantly up to a fraction of $0-75 \mu \mathrm{m}$. Studies $[16$, 17] also note the need to control such important indicators as the initial water-holding capacity (WHC) of non-milled (primary) granulate and the actual moisture content (AMC). AMC of the ready-for-shipment granulate, depending on its production technology, can change within $8-24 \%$. Accordingly, the consumption of water during granulation, including the losses on steam emission may constitute rather impressive figures from 1 to $3.5 \mathrm{~m}^{3} / \mathrm{t}$. Moreover, the pellicular moisture and the water retained in the pores of granules represent the unnecessary dead weight at transportation. The need of its evaporation during the production of building and ceramic materials leads to an essential overspend of fuel materials used for the purpose. In addition, the freezing of the transported wet granulated material in wintertime is quite frequent, also leading to great problems in servicing railroad freight cars.

Modern technological approaches mainly aimed at the handling of the problem of quality improvement of the slag granulate by reducing the WHC and AMC directed at controlling the size and shape of the obtained grains towards an essential lowering of the specific share of fine fraction $<1 \div 1.25 \mathrm{~mm}[17,18,26]$. However, with the growth in size of granules, the temperature conditions of cooling worsened, and the HAGP formation is less intensive. Deterioration of the activity of slag granulate leads to the need for additional chemical, mechanical, or thermal activation, which worsens the technical and economic indicators of its application [27-29].

From the point of view of the maximum useful use of the resource potential of treatment slag melts, the issue of extraction of metal and graphite inclusions present in it also deserves special attention. According to the study [30], the content of metal scrap and free (flake) graphite in metallurgical slags can vary within 4-6 and 4.5-15\%, respectively. The method of metal and graphite inclusions extraction proposed here, provides mechanical or explosive grinding of solid slag to $0-10 \mathrm{~mm}$ in dimension, followed by gravity-magnetic and aeration separation of the formed fine slag-metalgraphite mechanical mixture. The process is very time-consuming, costly, and environmentally unsafe (dusty). In addition, known is a method of extracting free graphite from slag by acid leaching of products of its mechanical separation (graphite is precipitated in the cake) [31, 32].

In case of substantial, purposeful modernization, the technology of wet granulation of slag melts can successfully combine the function of separation machining. But, the most important thing to note is that only wet granulation is able to continuously, with high productivity, produce $99 \%$ amorphous granulate [33,34], because of which it will always have an advantage over dry granulation methods. According to a study [33], the main condition for achieving such a high degree of amorphization is the need to keep the slag superheat at $160 \mathrm{~K}$, above the glass transition temperature $T_{\mathrm{g}}\left(T_{\mathrm{g}} \geq T_{\text {liq }}\right)$, with a cooling (quenching) rate of $2.6 \times 10^{5} \mathrm{~K} \mathrm{~s}^{-1}$. However, the problem of managing such 
important indicators of the quality of primary (not milled) granulate, as HWC and AMC, neither in these nor in other studies, is not investigated. The problem of selfabrasion (self-grinding and dusting) is also poorly studied, which during transportation, stockpiling and application of these raw materials leads to both undesirable losses and dust pollution of the surrounding air basin. Since WHC and AMC depend on the degree of surface roughness and external (open) porosity of granules, and the resistance to self-abrasion-on the structural and mechanical strength, the control of these characteristics becomes a very topical task.

Based on the above analysis, the purpose of this study and its novelty is to create and investigate a new, improved technology and equipment of high-speed wet granulation of slag melts, providing the maximum yield of hyper-quenched, mechanically strong and dense, abrasion-resistant amorphous glassy granules with reduced surface roughness, with minimal WHC and AMC, purified from metal and graphite inclusions.

The solution of this problem requires an updated approach to wet granulation technology, the essence of which should be to ensure high-speed fine fractional $<1 \mathrm{~mm}$ dispersion of molten slag with the maximum possible degree of overcooling (amorphization) and complete exclusion of the effect of steam-gas swelling and perforation.

Creation of such conditions is possible in case of using a special, closed, sharply expanding granulation chamber, with the function of forced internal high-speed vortex convection of water flowing around the dispersable slag stream (jet), thus creating an axial (vertically directed) continuous wave of hydraulic rarefaction (vacuum).

\section{Materials and methods}

In the experimental studies, we used production slags from the Rustavi Metallurgical Plant (Georgia), which were melted in a laboratory single-phase electric arc furnace with an active power of $100 \mathrm{kVA}$. The oxide melts obtained for the experimental studies corresponded by their chemical composition to the slags from the production of gray and foundry pig iron (GPIS and FPIS) and to the low-carbon constructional electrical steel (LCCESS). The experimental research took place in the foundry of the Georgian State Scientific Technical Center "Delta."

The chemical composition and such particularly significant technological characteristics as the basicity modulus $(\mathrm{BM})\left[\mathrm{BM}=(\mathrm{CaO}+\mathrm{MgO}) /\left(\mathrm{SiO}_{2}+\mathrm{Al}_{2} \mathrm{O}_{3}\right)\right]$, the activity modulus $(\mathrm{AM})\left[\mathrm{AM}=\mathrm{Al}_{2} \mathrm{O}_{3} / \mathrm{SiO}_{2}\right]$, the initial granulation temperature- $\mathrm{T}, \mathrm{K}$, and viscosity $-\mu, \mathrm{Pa} \cdot \mathrm{s}$ are presented in Table 1 . The content of metallic inclusions (beads with a diameter of $3 \mathrm{~mm}$ or less) in GPIS is $4.3 \%$, in FPIS $-5.2 \%$, and in LCCESS $-7.5 \%$ and the content of flake graphite-4.5, 6, and 8.4\%, respectively. Characteristics of technical water used for wet granulation are as follows: initial temperature-293 K; weakly acidneutral medium- $\mathrm{pH}$ 6.5-7.5; average mineralization, dry residue-200-400 mg/dm ${ }^{3}$;

Table 1 Types and main indicators of processable slag melts

\begin{tabular}{|c|c|c|c|c|c|c|c|c|c|c|c|}
\hline \multirow{2}{*}{$\begin{array}{l}\text { Slag } \\
\text { melt }\end{array}$} & \multicolumn{7}{|c|}{ Content of main components, $\%$} & \multirow[t]{2}{*}{ BM } & \multirow[t]{2}{*}{$\mathrm{AM}$} & \multirow[t]{2}{*}{$\mathrm{T}, \mathrm{K}$} & \multirow{2}{*}{$\begin{array}{l}\mu, \\
\text { Pa.s }\end{array}$} \\
\hline & $\mathrm{SiO}_{2}$ & $\mathrm{CaO}$ & $\mathrm{Al}_{2} \mathrm{O}_{3}$ & $\mathrm{MgO}$ & $\mathrm{FeO}$ & $\mathrm{MnO}$ & $S$ & & & & \\
\hline GPIS & 31.38 & 43.68 & 13.1 & 8.8 & 0.92 & 0.28 & 1.42 & 1.17 & 0.41 & 1720 & 0.35 \\
\hline FPIS & 32.9 & 44.3 & 11.5 & 8.5 & 0.85 & 0.25 & 0.95 & 1.18 & 0.34 & 1750 & 0.38 \\
\hline LCCESS & 25.8 & 51.6 & 7.15 & 12.8 & 0.75 & 0.24 & 0.7 & 1.95 & 0.27 & 1830 & 0.45 \\
\hline
\end{tabular}


average hardness $-3-5 \mathrm{mg}-\mathrm{eq} / \mathrm{dm}^{3}$; high transparency, suspended solids content -4.5 $\mathrm{mg} / \mathrm{dm}^{3}$.

For experimental investigation, we used our developed pilot semi-industrial hydrovacuum unit for dispersion of metallurgical melts [35]. Based on the results of our previous studies [36-38], we can state that the advantages of this innovative approach lie in the complex hydrodynamic-cavitation-vacuum thermomechanical treatment of vertically sucked and dispersible melt. The conditions for disintegration and cooling of the granulated slag melt created here are radically different from all of the above-discussed treatment methods.

The metallurgical melts hydro-vacuum dispersion process, when adapted to specific conditions of granulation of slag melts in the iron, steel, and ferroalloy production in blast and electric arc furnace, schematically illustrated in the Fig.1. At the same time, the developed new technological system for the processing of slag melts additionally solved such acute problems as separation/extraction of particularly valuable metallic inclusions and settling of the flake graphite washed-out from the slag.

The experimental semi-industrial plant of hydro-vacuum granulation of slag melts, which was tested at the State Scientific and Technical Center "Delta," is illustrated in Fig. 2.

Main operating conditions of a hydro-vacuum plant are as follows: supplied water pressure $-15 \div 16$ bar, water supply feed $-150 \div 200 \mathrm{~m}^{3} / \mathrm{h}$, suction capacity- $0.8 \div 0.9$ bar, diameter of the operating channel of the replaceable melt-supplying tip-15 $\div 30 \mathrm{~mm}$, diameter of the outer cylindrical body of the plant- $150 \mathrm{~mm}$, inside diameter of the diffusor-dispenser-100 $\mathrm{mm}$, plant height $-2 \mathrm{~m}$, occupied area-15, and performance$150 \div 300 \mathrm{~kg} / \mathrm{min}$.

Disintegration of vertically pumped slag melt, separation of metallic and graphite inclusions, and subsequent fine crushing of slag droplets are carried out by means of

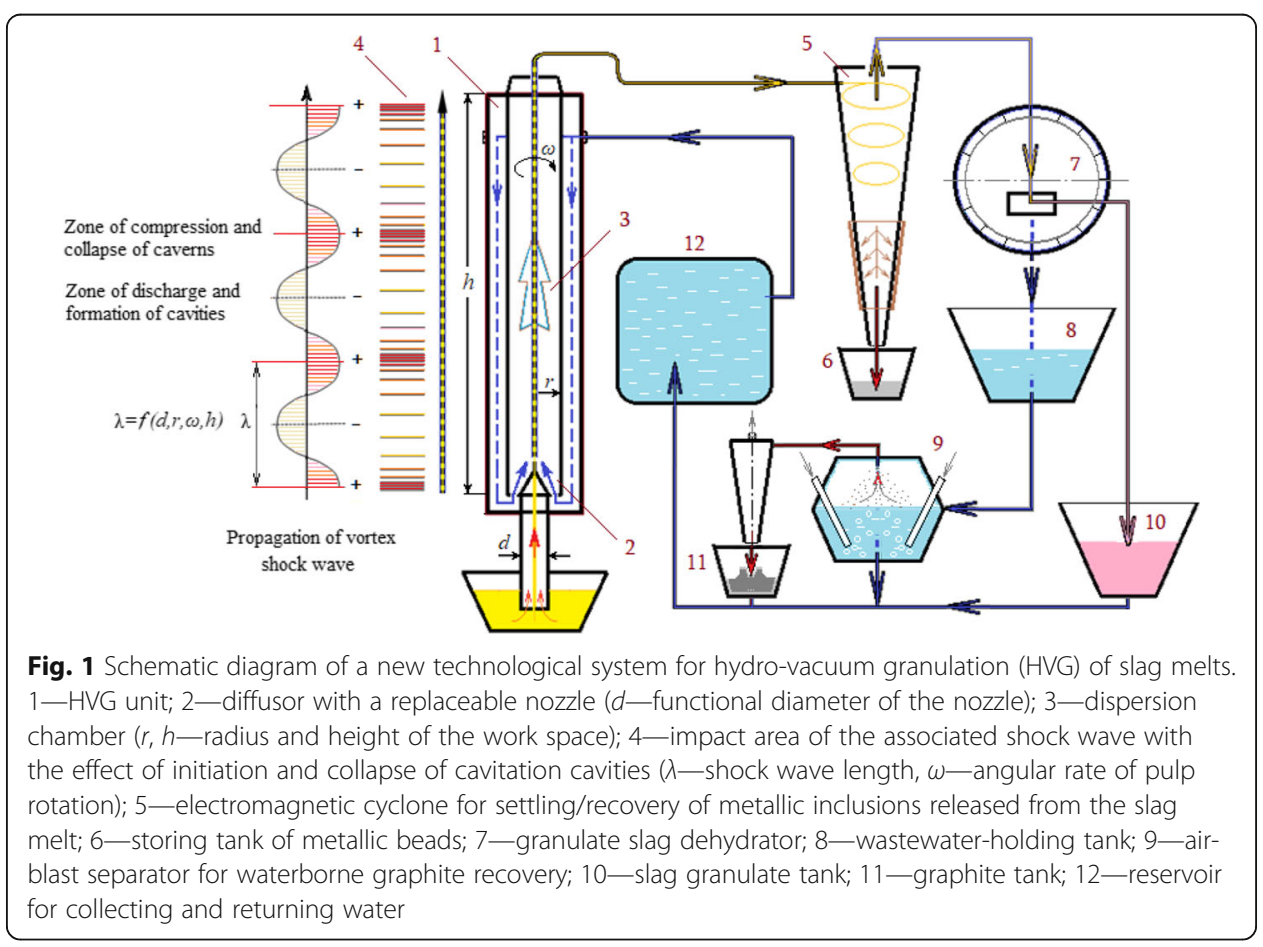



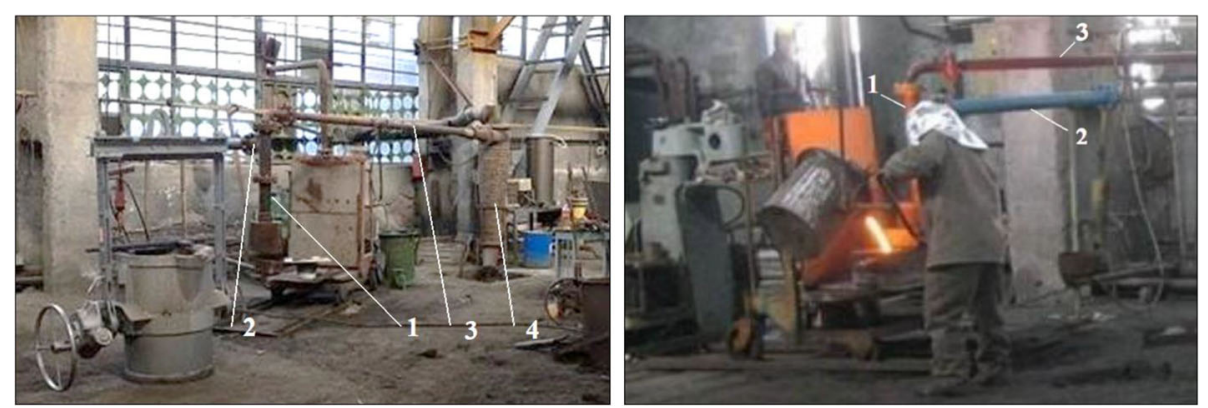

Fig. 2 Plant for hydro-vacuum granulation of melts. 1-hydro-vacuum exhaust and dispersion unit; 2-high-pressure water supply system; 3-pulp disposal hydrosystem; 4-electromagnetic cyclone for catching separated metallic beads

tangential and angular water-jet blows of the toroidal water blast generated in the diffusor (2) of the vertically located hydro-vacuum plant (1). This dribble is also subjected to the force impact from numerous high-power and high-frequency shock waves (4), originating at the formation of the alternating pulsed field (front) of the tangential (axial) pressure. The so generated cavitation processes continue to fine the setting particles of the disintegrated melt. Totality of the processes of cavitation ultrasound shock treatment, due to the raised potential of inertial acceleration releases the remaining in the slag dribble the finest metallic beads. At that, the high-speed quenching and volumetric contraction of the settling particles lead to the formation of new cracks, resulting in the release of the sour gas localized in the slag particles. The dynamic, high-speed solution and removal of gases and steam formed in the granulation process from the centers of their emission lead to a decrease in the structure swelling and perforation.

Based on the above features of the HVG process, its main advantage could be named the ensuring of forced high-speed cellular convection of the water supplied to the dispersion unit, where, in contrast to conventional granulation technologies, the disintegration process is restricted by the formation of local microsecond pulse zones of the undeveloped bubble boiling, at which the generated vapor-gas formations fail to impact aggressively the forming structure of solidifying slag melt particles and do not contribute to its swelling and perforation. Consequently, slag grains produced by hydrovacuum granulation will be distinguished by their structural homogeneity, density, thin-walled (flake shape), and a high gradient of quenching.

For morphological analysis of the surfaces of the obtained granules, the method of scanning electron microscopy (SEM) was used; the method of energy-dispersive X-ray analysis (EDS) was used to determine the elemental composition of these samples, and the method of X-ray diffraction analysis (XRD) was used to determine the phase composition. Methods of differential thermal and thermogravimetric analysis were used to study chemical and physicochemical processes occurring in a substance under conditions of temperature regime change (phase transformations).

The indicator of the development (roughness) of the granule surface, important in terms of its water-holding capacity, was determined by the method of optical profilometry. A liquid (kerosene) pycnometer method was used to evaluate porosity. To assess the abrasion resistance, a TUMBLER $1000 \mathrm{R}$ tester (EN 15210-1) was used. For a 
quantitative assessment of hydraulic activity of the obtained granules, the lime absorption method $(\mathrm{CaO})$ was used [39]. For this purpose, hydrate of lime $\left(\mathrm{Ca}(\mathrm{OH})_{2}\right)$ with the density of $1.0 \mathrm{~g} / \mathrm{cm}^{3}$ was prepared. The $\mathrm{CaO}$ concentration change was controlled with a 24-h periodicity by a titrimetric method and $1 \mathrm{H}$ solution of hydrochloric acid, according to GOST 22688-2018 [40]. The experimental data were processed by the method of analysis of variance.

\section{Results}

The morphology and EDS and XRD spectrograms of granules obtained by hydrovacuum granulation of the most demanded slag melt GPIS presented in Fig. 3, where image (a) shows that the grain surface is smooth and glassy, without crystalline-ribbed roughness, grains do not contain open (through) pores and metallic inclusions. Relatively small granules consist smoother and more transparent glass formations. For a comparative analysis of surface morphology, Fig. 4 shows SEM images of the granules obtained by traditional and proposed wet granulation methods. The average height of the protrusions on the surface of conventional granules, as determined by optical profilometry, is on average $35 \mu \mathrm{m}$ and the average depth of the grooves is $45 \mu \mathrm{m}$. The average height of the protrusions on HVG granules is only $5 \mu \mathrm{m}$, and the depth of the grooves is practically non-existent, which gives the latter a significant advantage in terms of moisture holding capacity.

The result of X-ray phase spectral analysis of granulated GPIS melt Fig. 3(b) (grain size $0.5-1 \mathrm{~mm}$ ) shows that the obtained diffractogram does not reveal clearly distinguished diffraction peaks of the crystal component, the structure mainly consists of a glassy, hydraulically active amorphous phase, but the background presence of inclusions of mineral formations close in composition to gehlenite $\mathrm{Ca}_{2} \mathrm{Al}_{2} \mathrm{SiO}_{7}$, merwinite $\mathrm{Ca}_{3} \mathrm{Mg}\left(\mathrm{SiO}_{4}\right)_{2}$, shennonite $\left(\gamma-2 \mathrm{CaO} \cdot \mathrm{SiO}_{2}\right)$, larnite $\left(\beta-2 \mathrm{CaO} \cdot \mathrm{SiO}_{2}\right)$, goethite $(\alpha-\mathrm{FeO} \cdot \mathrm{OH})$, and hematite $\left(\alpha-\mathrm{Fe}_{2} \mathrm{O}_{3}\right)$ is still identified. The number of inclusions of the noted mineral formation (MF) is reduced when the grain size of granulate (D, $\mathrm{mm}$ ) decreases by dependence $\mathrm{MF}=0.8 \mathrm{D}+0.36$, which is possible by increasing the degree of hydrovacuum crushing and quenching by increasing the pressure of water supplied to the hydro-vacuum disperser (Fig. 1, positions 2 and 3). It is noteworthy that the slags granulated by traditional methods also contain crystalline inclusions of acermanite $\left(\mathrm{Ca}_{2} \mathrm{Mg}\left(\mathrm{Si}_{2} \mathrm{O}_{7}\right)\right)$, manganolite $\left(\mathrm{Ca}_{3} \mathrm{Mg}\left(\mathrm{SiO}_{4}\right)_{2}\right)$, melilite $\left(\mathrm{Ca}_{2}\left(\mathrm{Mg}_{0.5} \mathrm{Al}_{0.5}\right) \cdot\left(\mathrm{Si}_{1.5} \mathrm{Al}_{0.5} \mathrm{O}_{7}\right)\right)$ and merwinite $\left(\mathrm{Ca}_{3} \mathrm{Mg}\left(\mathrm{SiO}_{4}\right)_{2}\right)$, which makes them noticeably inferior in hydraulic
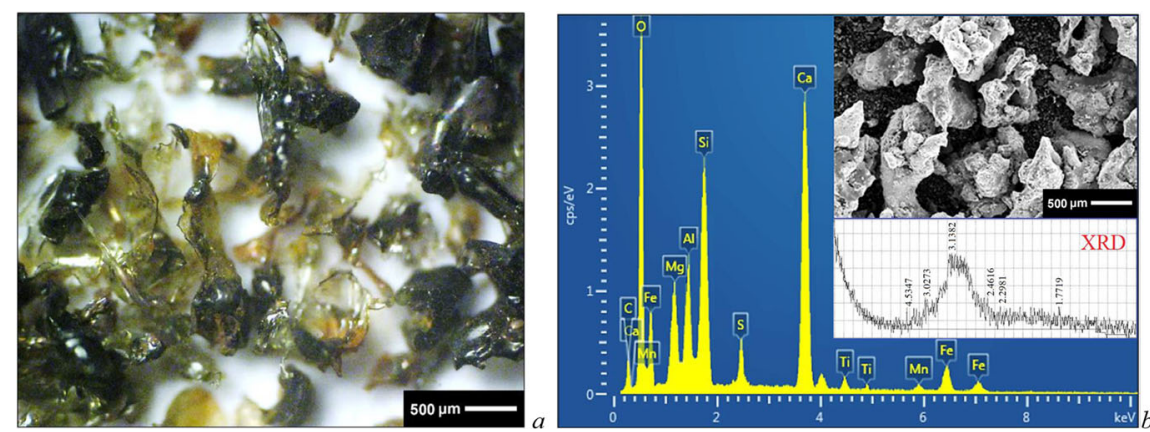

Fig. 3 Morphology (a) and EDS and XRD spectrograms of granule (b) obtained by the hydro-vacuum granulation of GPIS 


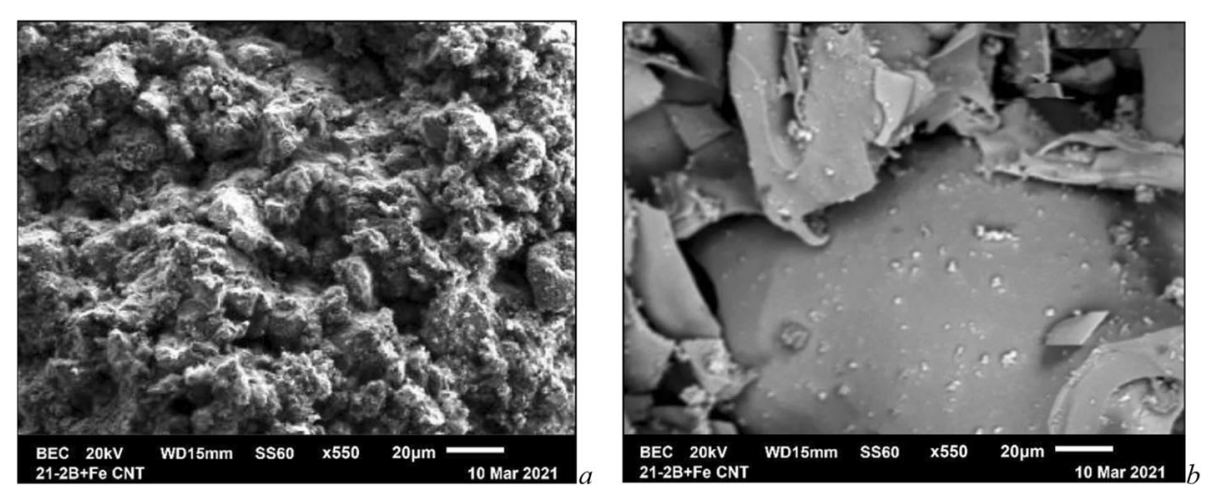

Fig. 4 Typical microrelief of granules surfaces obtained by hydro-channel granulation of GPIS (grain size 2 $\mathrm{mm})(\mathbf{a})$; the same in hydro-vacuum granulation (grain size $0.2 \mathrm{~mm})(\mathbf{b})$

activity to HVG granulate. In contrast to the conventional granulation technologies, in which the glassy phase content (HAGP) in the obtained granules is unstable and varies depending on their grain size, degree of loosening, swelling and volume overcooling (quenching), the HVG process can stably produce granules homogeneous in key characteristics and properties, which once again emphasizes its high efficiency.

The high degree of glazing of HVG granules is also evidenced by the results of differential thermal analysis, which are illustrated in Fig. 5. The derivatogram of HVG granules shows that at $1170 \mathrm{~K}$ an exothermic effect (release of latent heat) corresponding to the glass crystallization (reverse phase transformation from amorphous to crystalline state) is observed. It is preceded by endothermic effect (without mass loss) at $1130 \mathrm{~K}$ related to energy expenditures on bond rearrangements in the glassy phase before its crystallization. The endothermic effect at $1090 \mathrm{~K}$ may be caused by the polymorphic transformation of shennonite $(\gamma \rightarrow \alpha)$. The broad endothermic effect at $1225 \mathrm{~K}$ corresponds to the beginning of glassy amorphous phase decomposition. For hematite $(\alpha-$ $\mathrm{Fe}_{2} \mathrm{O}_{3}$ ), a small endothermic effect at $990 \mathrm{~K}$ caused by its transition into $\gamma-\mathrm{Fe}_{2} \mathrm{O}_{3}$ maghemite is characteristic, accompanied by an abrupt change in properties.

Crystalline iron oxide monohydrates have three modifications: $\alpha$ (goethite), $\beta$, and $\gamma$ (lepidocrocite). The differential curve of goethite $(\alpha-\mathrm{FeO} \cdot \mathrm{OH})$ has an endothermic effect in the temperature range from 600 to $690 \mathrm{~K}$ caused by its dehydration with transition to anhydrous crystal form $\alpha-\mathrm{Fe}_{2} \mathrm{O}_{3}$ (hematite). On the DTA curve, the endothermic effect also appears at $990 \mathrm{~K}$, which is associated with the polymorphic transformation of $\alpha-\mathrm{Fe}_{2} \mathrm{O}_{3}$ into $\gamma-\mathrm{Fe}_{2} \mathrm{O}_{3}$. A broad endothermic effect at $410 \mathrm{~K}$ is associated with removal of adsorbed moisture on the surface of the slag particle. Small endothermic effects at 470,550 , and $600 \mathrm{~K}$ are caused by the removal of hygroscopic moisture in $\beta$-modified iron oxide monohydrate $(\beta-\mathrm{FeO} \cdot \mathrm{OH})$, the content of which does not exceed $0.5 \mathrm{wt} . \%$. Analysis of phase transformations with accompanying mass losses shows that the content of the crystalline phase in the granules does not exceed $1.5-1.6 \%$. Thus, we can conclude that the GPIS granulate obtained by hydro-vacuum granulation on average by $98.5 \%$ consists of glassy, solidified in the amorphous state grains with micro inclusions of crystalline dicalcium silicate (shennonite, larnite), iron oxides (hematite, maghemite), and their hydrates (goethite, lepidocrocite). The phase composition of HVG granulate produced from FPIS melt practically did not differ from 


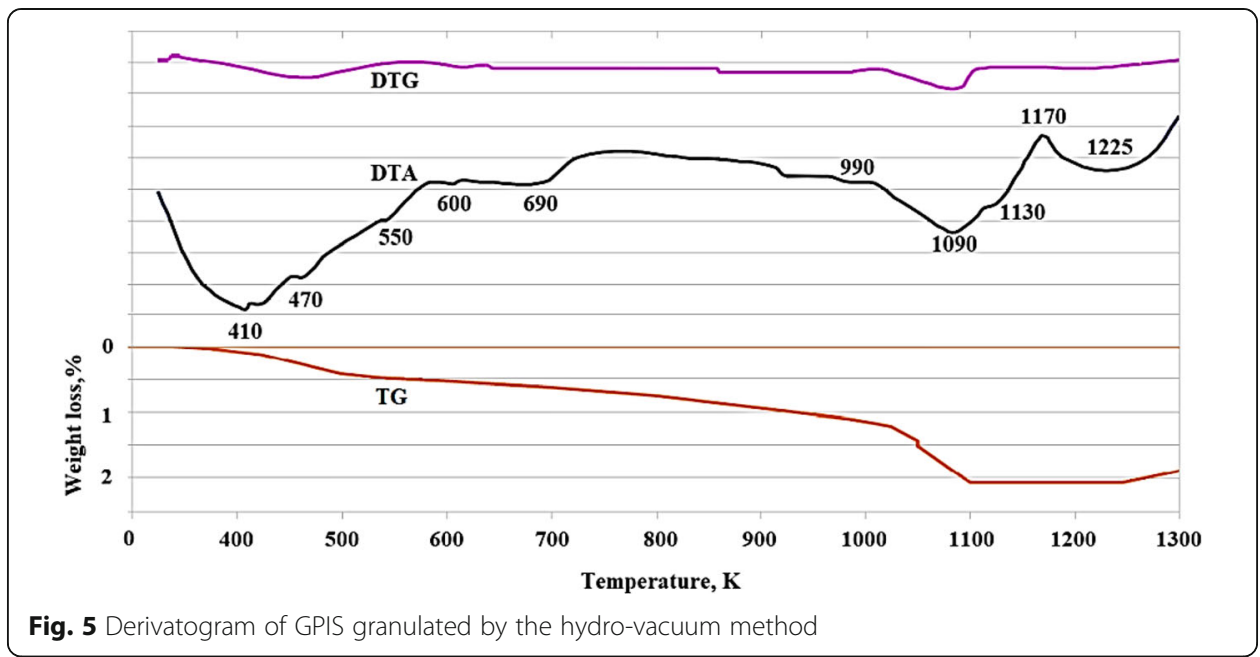

GPIS granulate. The only difference is the decrease in the ratio between of mineral compounds of $\mathrm{Ca}_{2} \mathrm{Al}_{2} \mathrm{SiO}_{7}$ to $\mathrm{Ca}_{3} \mathrm{Mg}\left(\mathrm{SiO}_{4}\right)_{2}$ by $18-20 \%$ (graphically unrepresented). In turn, the phase composition of the LCCESS granulated by the hydro-vacuum method was slightly different from composition of GPIS. In particular, the samples were 95$96 \%$ composed of the glassy phase, with inclusions of merwinite $\left(\mathrm{Ca}_{3} \mathrm{Mg}\left(\mathrm{SiO}_{4}\right)_{2}\right)$, magnesioferrite $\left(\mathrm{MgFe}_{2} \mathrm{O}_{4}\right)$, larnite $\left(\mathrm{Ca}_{2} \mathrm{SiO}_{4}\right)$, wustite $(\mathrm{FeO})$, and goethite $(\mathrm{FeO} \cdot \mathrm{OH})$. In spite of the fact that HVG granulate LCCESS also consisted to a high degree of the glassy phase, its hydraulic activity was still significantly lower (by 25-20\%) than that of HVG slag GPIS and FPIS, which can be explained by its relatively low AM (Table 1).

The results of the study of hydraulic activity of the most highly demanded GPIS granulate are given in Fig. 6, where the impact of granule size (D, $\mathrm{mm}$ ) and the length of reaction with the lime (in days) per value of its absorption in milligram per gram is illustrated. The comparative deceleration of the lime absorption rate observed in granules of higher grain size can be explained by both a decrease in the specific area of the reacted surfaces and a possible rise in the presence of above noted microcrystalline mineral formations $(\mathrm{MF}=0.8 \mathrm{D}+0.36)$.

Figure 6 shows that the average $\mathrm{CaO}$-absorption activity of granules produced in the HVG process makes $600-650 \mathrm{mg} / \mathrm{g}$, which is almost two times higher than that of slag granulated by traditional technologies (320-360 mg/g [41]). This testifies to the obvious advantage of the technological conditions of high-speed degassing, globular-thin-walled (flake) dispersion, and high-gradient quenching, created during hydro-vacuum granulation of the slag melt.

Since the granulate activity depends to a considerable extent on its grain particle size (D, mm), an investigation for detecting the factors of its control was carried out. The main factors of technological were found to be the temperature $(\mathrm{T}, \mathrm{K})$ and the internal diameter of the melt feeding nozzle, i.e., the flow fed in the diffusor (d, $\mathrm{mm}$ ).

The main results of this research are given in Fig. 7. From Fig. 7 (1), it can be seen that at hydro-vacuum granulation of the close in chemical composition GPIS and FPIS melts, at the $15 \mathrm{~mm}$ diameter of the feeding flow, the treatment temperature decrease from 1720 to $1600 \mathrm{~K}$ which leads to the coarsening of the produced at the output granules from 0.2 to $1.9-2 \mathrm{~mm}$. At treatment, flow $d=20 \mathrm{~mm}$, and the average diameter of 


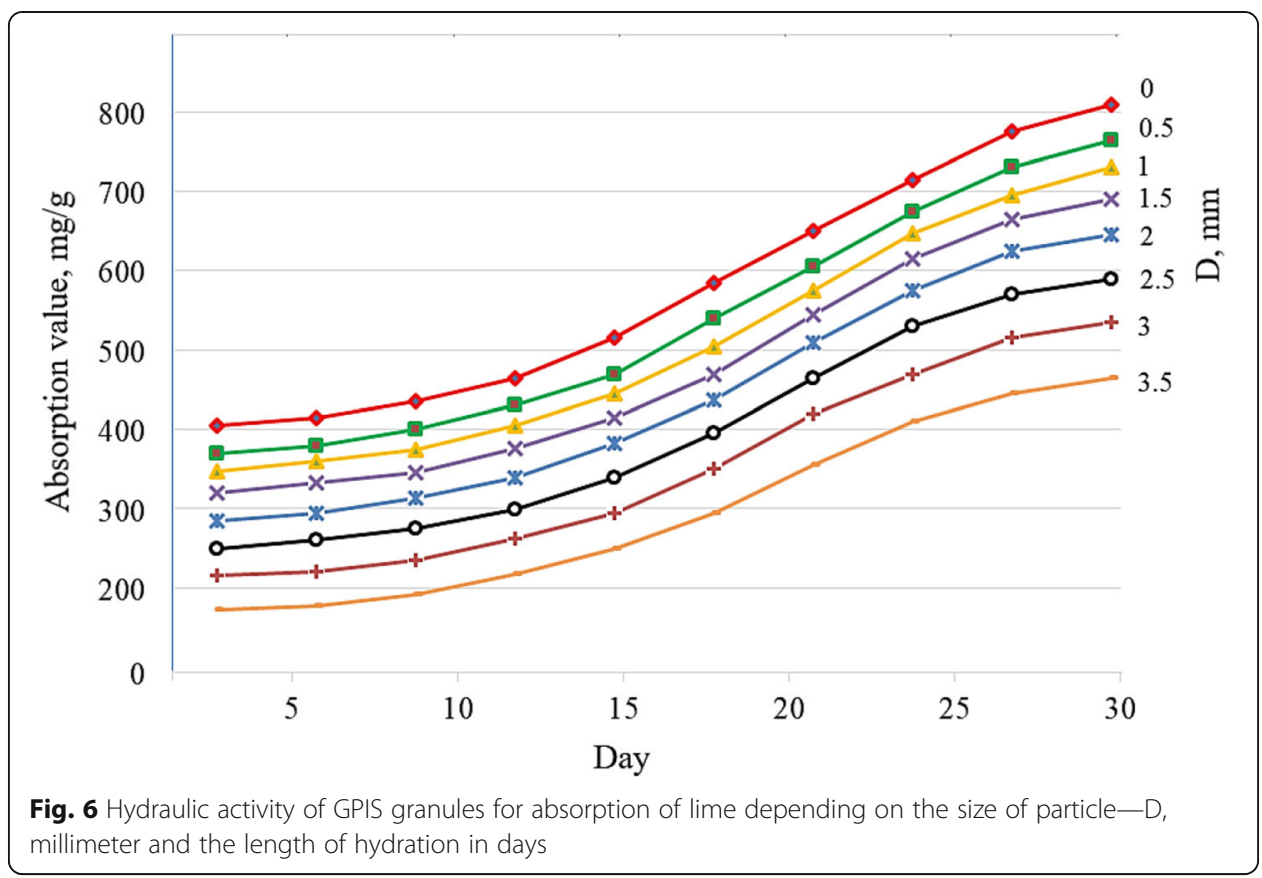

the granules grows from $0.26-0.3 \mathrm{~mm}$ to $2.4-2.5 \mathrm{~mm}$. An increase in the flow diameter up to $25 \mathrm{~mm}$ gives an increase in the size of granules from $0.33-0.35$ to $2.9-3 \mathrm{~mm}$; during dispersion of the $30-\mathrm{mm}$ flow, the granules coarsen from $0.4 \mathrm{~mm}$ to $3.5-3.7$ $\mathrm{mm}$. In turn, Fig 7 (2) shows that during treatment of the relatively viscous LCCESS melt, a reduction of its initial temperature from 1830 to $1690 \mathrm{~K}$, at dispersion of the 15 $\mathrm{mm}$ diameter flow, is accompanied with the coarsening of the average size of granules from 0.25 to $2.2 \mathrm{~mm}$. An increase in the diameter up to $30 \mathrm{~mm}$ and accordingly as relative doubling of the melt supply rate at the given temperature range led to the coarsening of the granules from 0.4 to $4.3 \mathrm{~mm}$.

Figure 7 graphical dependences indicate on the existence of a stable essential correlation between the controlled parameter (grain size) and regulated technological melt treatment modes, which, in turn, can become an functional lever to operating control of the HVG process efficiency by choosing the rational values of these modes.

Analysis of the laboratory data showed that the fine, thin-walled semi-transparent particles of average size of $0.5-0.4 \mathrm{~mm}$ and lower are distinguished by the highest activity. Based on the above, the temperature meeting the condition $\mathrm{D} \leq 0.5 \mathrm{~mm}$ could be taken as the temperature threshold of high efficiency of the HVG process. Based on the noted threshold criterion and data with given in Fig. 7 (1), the rational temperature for the GPIS and FPIS melts can be considered $1680 \mathrm{~K}$. In its turn, the recommended temperature for the LCCESS melt is $1790 \mathrm{~K}$.

Laboratory studies on the porosity and abrasion resistance of granules obtained by the HVG method, similarly to studies on hydraulic activity, showed a clear advantage of the HVG process over traditional granulation methods. On average, the porosity of HVG granules, depending on their fractionality $(0-4 \mathrm{~mm})$, was in the range of 5-20\%, which is actually $2.5-3$ times lower than the porosity of granules produced by traditional wet methods. In turn, the loss of mass during self-abrasion was $3-5 \%$, which is 


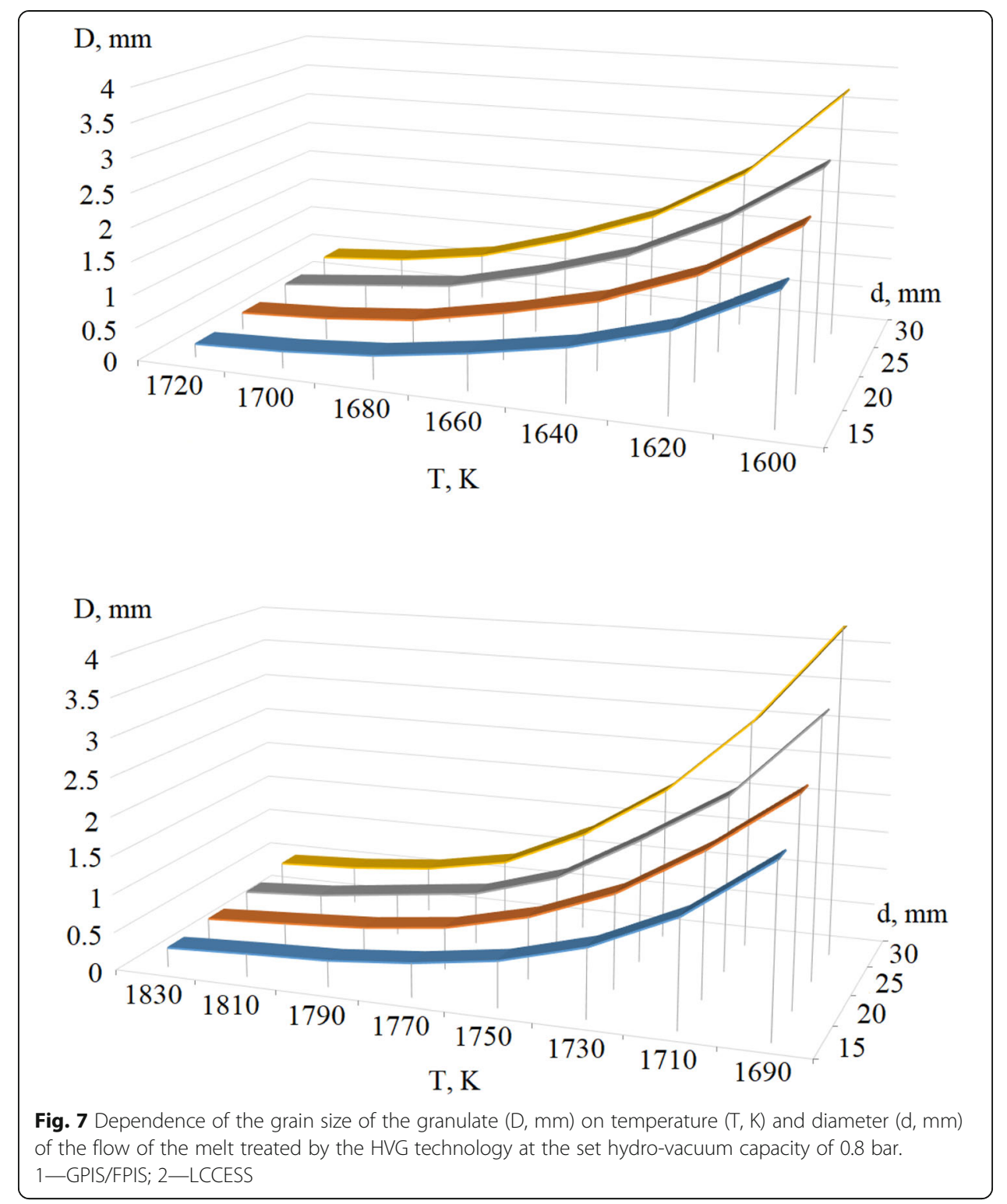

3.5-4 times lower than the index of abrasibility of granulated slag produced by traditional technologies.

The application of the similar method for assessing the HVG process efficiency by the operational characteristics of WHC and AMC showed that in contrast to the conventional hydromechanical INBA or VNIIMT technologies, where the WHC of the obtained from GPIS и FPIS granulate, depending on the grain particle size, can vary within $45-50 \%$, the AMC $24-20 \%$, during hydro-vacuum granulation, the WHC reduced to $25-13 \%$, and the AMC to $4-6 \%$. The noted quality indicators also significantly improve in the LCCESS granulate. Dependence of the WHC and AMC of granulate obtained by the HVG technique on its grain size is illustrated in Fig. 8.

The effect of perforation reduction degree and improvement of the WHC indicator is also clearly depicted in SEM images (Fig. 9), illustrating the surfaces of GPIS melt 


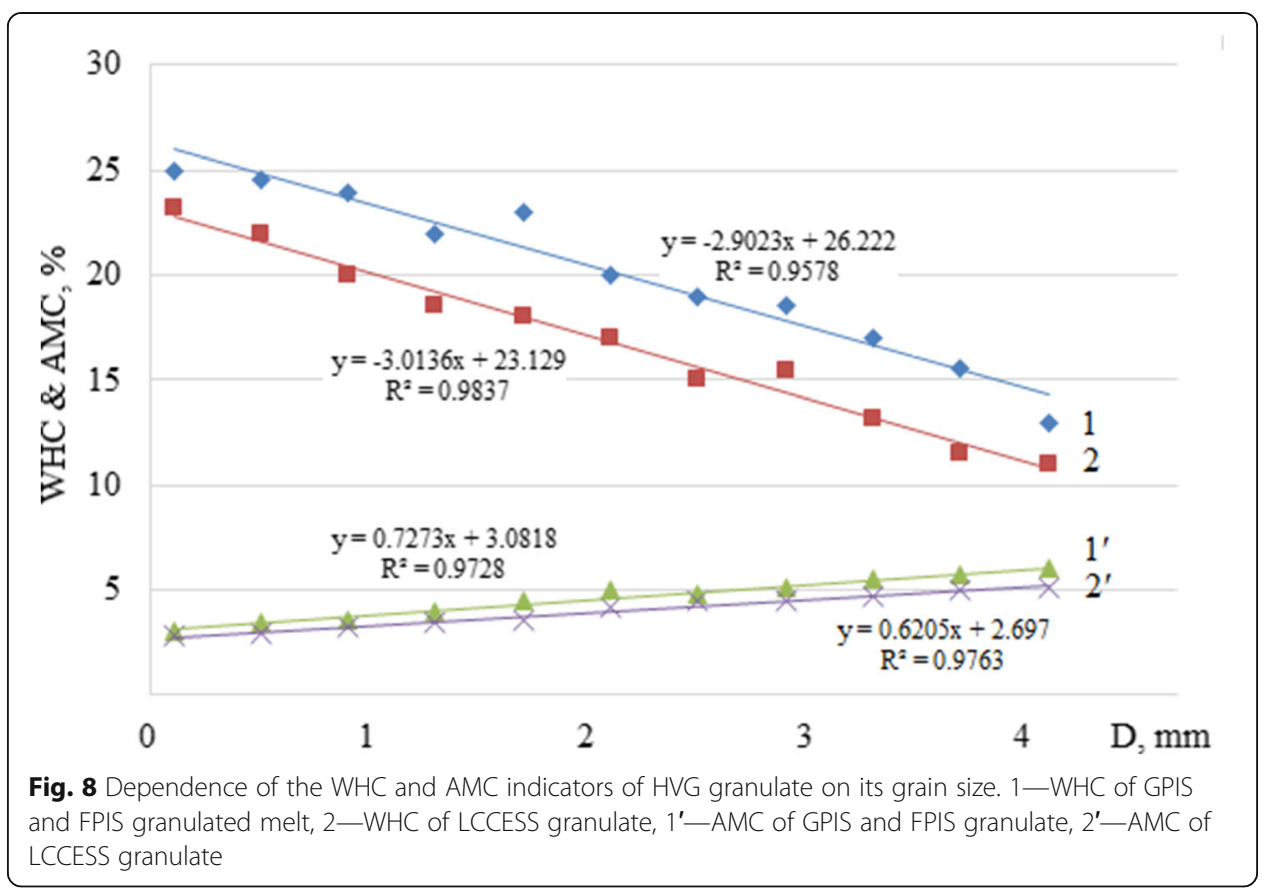

granules produced by the conventional hydro-channel (Fig. 9(1)) and the proposed hydro-vacuum technology under different temperature conditions of treatment (Fig. 9 (2-4)). The SEM images of surfaces of the granules produced by the HVG technique indicate on both an essential reduction of the chadded perforation and a reduction of the scale of volumetric swelling. At that, with a decrease in the granulation temperature from 1720 to $1680 \mathrm{~K}$, i.e., with a limiting increase in viscosity and surface tension of the processable melted slag, the structure and morphology of the granules are improved and stabilized. This effect is another proof of essential advantage and necessity of selecting an optimum temperature range of processing the melted slags in the process of their hydro-vacuum granulation. So, unlike new HVG process, in conventional technological processes of wet granulation, at technological losses of heat, decrease in temperature, and fluidity of processed slag melt, structure and morphology of granules with an increase in their grain size do not improve; on the contrary, their degree of swelling increases, degree of quenching decreases, and as a result, content of hydraulically active glassy amorphous phase can fall below the limiting value of $66.6 \%$, fixed by the European standard BS EN 15167-1: 2006. The self-abrasion rate also deteriorates, reaching $30 \%$ or more.

The HVG process also showed its high efficiency in terms of separation and extraction of metallic spherical particles and flake graphite included in the slag. Figure 10 shows the effect of separation of metal inclusions from slag melt (fractionality 50-200 $\mu \mathrm{m})$. The degree of extraction depending on the temperature and viscosity of the slag varies in the range of $90-95 \%$, a slightly lower index of graphite extraction-75-80\%. Studies on determination of rational approach and regimes of separation of granulated slag and metal and graphite inclusions present in it are still in progress.

A system analysis of advantages and features of the semi-industrial pilot HVG-plant showed that its operation for granulation of slag melts of ferrous metallurgy in enterprises equipped with modern arc electro-thermic ore-smelting furnaces is feasible 


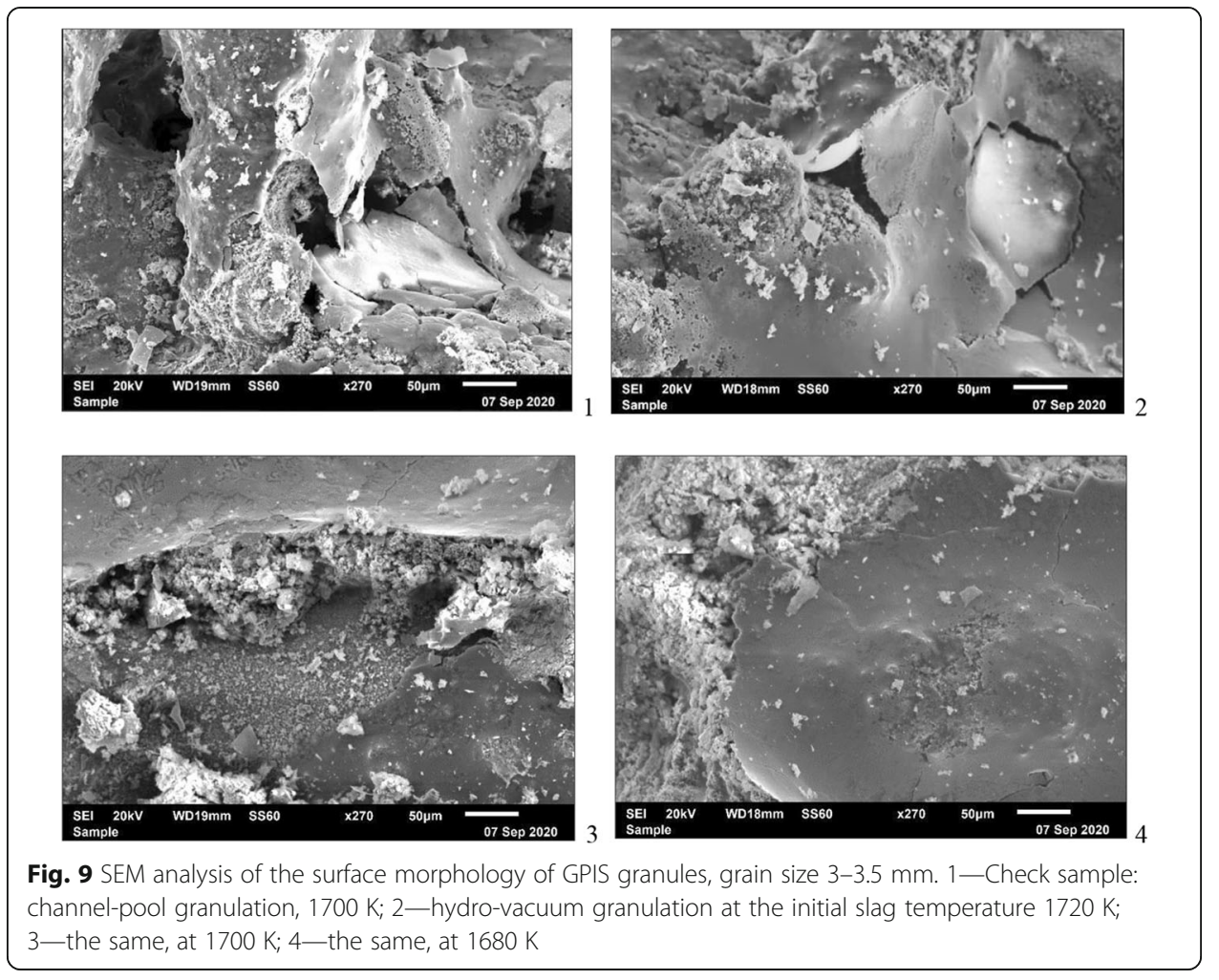

according to the schematic diagram presented in Fig. 11, where 1 is arc ore-thermal furnace, 2-chute for intake and primary processing (liquid-phase separation) of slagmetal melt mixture [42], 3-conveyer for casting liquid metal (LM) cleaned from associated slag, 4-container for receipt of solidified metal pigs (MP), 5-plant for hydro-vacuum suction and granulation of molten slag, 6-high-pressure water pump, 7-technological unit of continuous pulp (P) processing: separation and precipitation of metal inclusions, dehydration of slag granulate (SG), extraction of graphite (G), and return water supply, 8-granulated slag intake and final dehydration tanks, and 9-collector of extracted metallic beads (MB).

The pilot scale research of the proposed technological approach and plant for hydrovacuum granulation of metallurgical slag melts showed that its scaling under the real
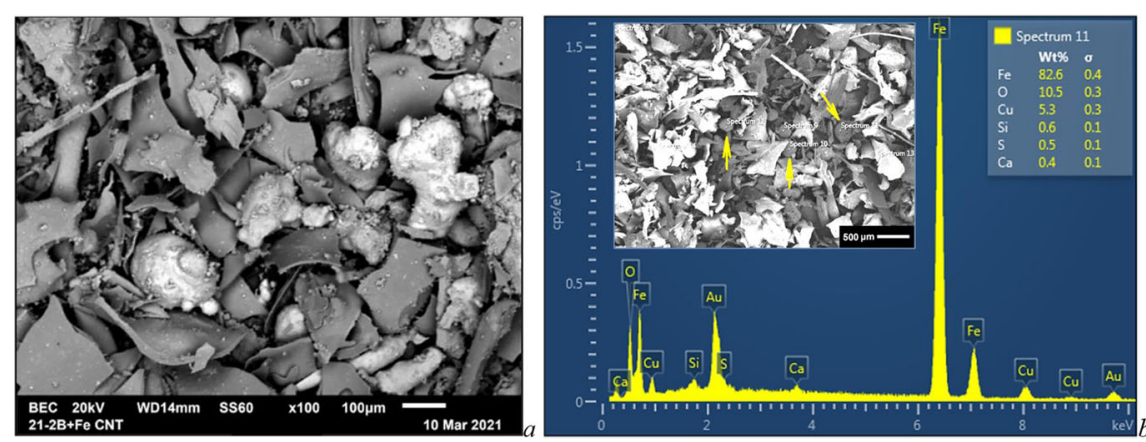

Fig. 10 Spherical metallic particles separated by HVG treatment of molten GPIS (a) and their EDS spectrogram (b) 


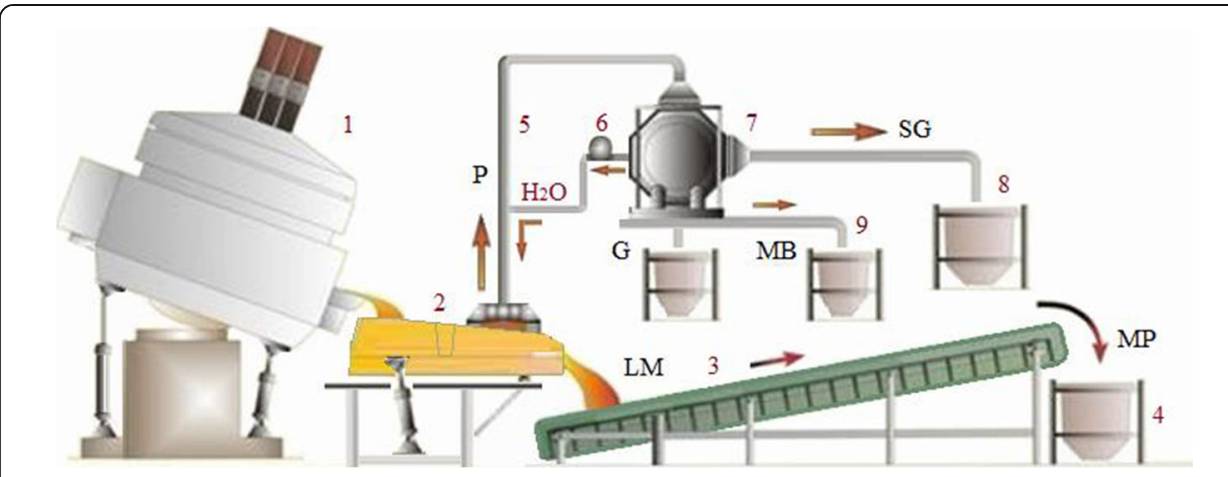

Fig. 11 Simplified schematic diagram of a new technological system for hydro-vacuum granulation of slag melts of ferrous metallurgy (designations-in the text)

industrial conditions will not be associated with outages and essential reconstruction of melting furnaces or the adjacent casting platform.

It was also revealed that in the case of significant overheating of the slag and the impossibility of regulating the temperature during hydro-vacuum treatment, the need to a proportional increase the pressure of the high-speed water flow used for granulation becomes paramount. A magnification in the feed rate and water pressure, together with an increase in the rate of suction (vacuuming capacity) and granulation of liquid slag, intensifies the heat removal process (accelerates the process of cooling and quenching the forming granules), which sufficiently compensates the deviation from the desired temperature regimes of processing. Due to the need to increase the water pressure, the power consumption increases only slightly, but with an increase in the productivity of the HVG-plant, this consumption is also fully compensated. Accordingly, the quality, safety, and economic performance of the HVG process do not deteriorate.

\section{Conclusion}

Based on the studies conducted, we can conclude that the proposed technological approach to granulation of slag melts is highly effective and has a number of significant advantages, in particular it is:

- Ensuring high-speed fine-fractional (flake) dispersion, degassing, and high-gradient quenching of slag melt with the elimination of swelling and vapor-gas perforation of hardening particles;

- Ensuring a high degree of quenching and amorphization, the content of the glassy phase 95-99\%, depending on the chemical composition and modulus of basicity and activity of the slag melt;

- High reliability and safety of functioning at the expense of high-speed inhibition of the vapor formation and boiling processes, practically complete exclusion emission of dust, vapor and noxious gases;

- Flexible control of the granulation process due to smooth regulating of technological modes (granulated slag temperature, suction jet diameter, suction power, water pressure);

- Producing a granule with reduced water-holding capacity (WHC) and actual moisture content $(\mathrm{AMC})$; 
- Possibility of separation and individual extraction of metal and graphite inclusions.

The rational temperature range of the hydro-vacuum granulation of molten slags of the gray and foundry pig iron is 1680-1660 K, during granulation of melted slags of low-carbon constructional steels the optimal is the temperature range 1790-1750 K.

On average, the porosity of HVG granules depending on their fractionality (4-0 $\mathrm{mm}$ ) is reduced up to $5 \%$, which leads to densification and refinement of the structure and reduction of self-abrasion index up to $3 \%$. According to these characteristics, the quality of HVG slag is several times better than products made by traditional technologies. The water-holding capacity and actual moisture content of HVG granules can be reduced by up to $25-13 \%$ and $6-4 \%$, respectively, and the hydraulic activity by $\mathrm{CaO}$ absorption index is increased up to $610-650 \mathrm{mg} / \mathrm{g}$.

Based on the above results, in general, it can be concluded that the problem of developing an improved technology and equipment for wet granulation of slag melts providing the maximum yield of highly quenched, mechanically strong and dense, abrasionresistant amorphous glassy hydraulic highly active granules with minimum waterholding capacity and moisture content has been successfully solved at the level of semiindustrial scale. Consequently, the proposed technological approach to granulation of slag melts has a prospect for further development and industrial implementation.

\section{Abbreviations}

AM: Slag activity modulus; AMC: Actual moisture content; BM: Slag basicity modulus; EDS: Energy-dispersive X-ray spectroscopy; FPIS: Foundry pig iron slag; HVG: Hydro-vacuum granulation; HAGP: Hydraulically active glassy phase; G: Graphite; GPIS: Gray pig iron slag; LCCESS: Low-carbon construction electrical steel slag; LM: Liquid metal; MP: Metal pigs; MF: Mineral formation; MB: Metallic beads; SEM: Scanning electron microscopy; P: Pulp; SG: Slag granulate;

$T_{\mathrm{g}}$ : Glass transition temperature; $T_{\text {liq }}$ : The liquidus temperature; WHC: Water-holding capacity; XRD: X-ray diffraction

Acknowledgements

Not applicable

\section{Authors' contributions}

DS, one of the key authors of the concept of hydro-vacuum dispersion of metallurgical melts, was engaged in the collection and analysis of literature and organized and supervised laboratory and experimental work. GJ, the author of the idea of hydro-vacuum granulation of slags with the extraction of metal and graphite inclusions from them, drew up a new processing scheme, carried out experimental work, processed the materials obtained, made diagrams, and made a great contribution to the compilation of the manuscript. GJ studied the operational properties of the obtained granules, on the basis of which he assessed the efficiency of the granulation process, and identified the criteria for managing the quality of the granulate. GS participated in the experimental research and made a significant contribution to the writing and translation of the manuscript in English. The authors read and approved the final manuscript.

Funding

Not applicable.

\section{Availability of data and materials}

The datasets used and/or analyzed during the current study are available from the corresponding author on reasonable request.

\section{Declarations}

Competing interests

The authors declare that they have no competing interests.

\section{Author details}

${ }^{1}$ Georgian Technical University, Tbilisi, Georgia. ${ }^{2}$ Metallurgical Engineering and Consulting Ltd., Tbilisi, Georgia. ${ }^{3}$ Akkord Cement, Kazakh, Azerbaijan. ${ }^{4} \mathrm{G}-$ Metal Ltd., Tbilisi, Georgia. 
Received: 19 April 2021 Accepted: 6 September 2021

Published online: 03 November 2021

\section{References}

1. Friedrich B (2019) Sustainable utilization of metals-processing, recovery and recycling. Metals 9(7):769. https://doi.org/1 $0.3390 /$ met 9070769

2. Dzhandieri GV (2020) Diagnostics of efficiency and optimization of the organizational and economic system of ferrous metals recycling. Chernye Metally, 1: 56-62. (In Russian) URL: https:/rudmet.ru/journal/1889/article/32107/

3. Bellemans I, de Wilde E, Moelans N, Verbeken K (2018) Metal losses in pyrometallurgical operations - a review. Adv Colloid Interface Sci 255:47-63. https://doi.org/10.1016/j.cis.2017.08.001

4. Jandieri G, Sakhvadze d., Raphava A. (2020) Manganese biomining from manganese-bearing industrial wastes of Georgia. J. Inst. Eng. India Ser. D 101(2):303-316. https://doi.org/10.1007/s40033-020-00235-0

5. Sorokin YV, Demin BL, Smirnov LA, YEN S (2020) Possibility of Slag Sensible Heat Recovery on Drum-like Installations. IV Congress "Fundamental research and applied developing of recycling and utilization processes of technogenic formations", KnE Materials Science, pp 586-592. https://doi.org/10.18502/kms.v6i1.8148

6. Jandieri G, Tsereteli N, Sakhvadze D, Tavadze G, Jishkarini G (2011) High productive energy-efficient technology for obtaining manganese-containing conglomerate from the mountainous-metallurgical industrial waste and thin-fraction concentrates. Anniversary Conference of Academician T. Loladze 100 y. - "Innovative technologies and materials" At: Georgian Technical University, Tbilisi, pp 147-155

7. Zimakova GA, Solonina VA, lljasova SV, Ashyrov MA (2019) Activation of metallurgical waste slag. Innov Invest 10:280284 (In Russian); https://cyberleninka.ru/article/n/aktivatsiya-metallurgicheskogo-otvalnogo-shlaka/viewer

8. Spilnik NV, Shcherbak SA (2013) Environmentally friendly building materials based on silicomanganese and blast furnace granulated slags. Bull Dnieper State Acad Civil Eng Architect 5:33-39 (In Russian)

9. Zhukov W, Khadzhishalapov GN (2004) Heat-resistant slag concrete based on high-alumina cement. Build Mater 6:1012 (In Russian); http://rifsm.ru/u/f/sm_06_04.pdf

10. Khaydarov BB, Suvorov DS, Kolesnikov EA, Mazov IN, Kuznetsov DV, Marushina AA, Zhukova PA (2017) Development of energy-efficient production technology and investigation of clinker-free binding materials based on blast-furnace granulated slags. Modern methods and technologies for creating and processing materials, Collection of scientific papers, Book 1. Materials science Minsk, Belarus, pp 243-252 https://www.elibrary.ru/download/elibrary_32841972_7754 7738.pdf

11. Ryshchenko MI, Bialystotskaya LA, Shchukina LP, Trusova YD, Pavlova LV, Galushka YO (2017) Utilization of metallurgical slags in the production of wall ceramics. Ecol IndustS 2:78-84 (In Russian); http://repository.kpi.kharkov.ua/handle/KhPIPress $/ 32269$

12. Hobotova E, Hrajvoronskaya I (2019) Sorption properties of metallurgical slags. Bull HNADU 84(84):88-97 (In Ukrainian). https://doi.org/10.30977/BUL.2219-5548.2019.84.0.88

13. Grubeša IN, Barišić I, Fucic A, Bansode S (2016) Application of blast furnace slag in civil engineering: Worldwide studies. In: Grubeša IN, Barišić I, Fucic A, Samitinjay S, Bansode J (eds) Characteristics and Uses of Steel Slag in Building Construction. Woodhead Publishing, pp 51-66. https://doi.org/10.1016/B978-0-08-100368-8.00004-X

14. Drachuk YZ, Stalinskaya E, Snitko E, Zavgorodnyaya E, Jaworska M, Savyuk L, Cheylyakh D (2021) Slag waste of metallurgical production. Environmental and economic justification of their use in industry in Ukraine. Polityka Energetyczna Energy Policy J 24(1):169-182. https://doi.org/10.33223/epj/131205

15. Leyser P, Cortina C (2005) INBA slag granulation system - environmental process control. Iron Steel Technol 2(4):139146 http://digital.library.aist.org/pages/PR-PM0405-6.htm

16. Filonenko AV (2018) Current technologies review of blast-furnace steelmaking slags recycling. Ecol Industry 3-4:91-104 (In Russian); https://www.elibrary.ru/item.asp?id=36905002\&

17. Kravchenko VP (2015) Slag melt granulation and factors affecting the quality of granulated slag. Bulletin of the Azov State Technical University. Series Techn Sci 30(1):51-58 (In Russian); https://www.elibrary.ru/item.asp?id=25469901

18. Tobo H, Watanabe K, Kuwayama M, Goto S, Goto H, Tanaka T (2015) Effect of water granulation conditions on density and grain size of granulated blast furnace slag. ISIJ International 55(11):2499-2508. https://doi.org/10.2355/isijinterna tional.ISIJINT-2015-254

19. YU P, Wang S, Li Y, XU G (2016) A review of granulation process for blast furnace slag. MATEC Web of Conferences 68, 6007. ICIEA 2016:1-4. https://doi.org/10.1051/matecconf/20166806007

20. Liu J, Yu Q, Zuo Z, Yang F, Duan W, Qin Q (2017) Blast furnace slag obtained from dry granulation method as a component in slag cement. Construct Building Mater 131:381-387. https://doi.org/10.1016/j.conbuildmat.2016.11.040

21. Chang Q, Li X, Ni H, Zhu W, Pan C, Hu S (2015) Modeling on dry centrifugal granulation process of molten blast furnace slag. ISIJ International 55(7):1361-1366. https://doi.org/10.2355/isijinternational.55.1361

22. Barati M, Jahanshahi S (2020) Granulation and heat recovery from metallurgical slags. J. Sustain. Metall 6(2):191-206. https://doi.org/10.1007/s40831-019-00256-4

23. Liu J, Yu Q, Zuo Z, Yang F, Han Z, Qin Q (2019) Reactivity and performance of dry granulation blast furnace slag cement. Cement Concrete Composit 95:19-24. https://doi.org/10.1016/j.cemconcomp.2018.10.008

24. Yuksel I (2018) 12 - Blast-furnace slag, Editor(s): Siddique R, Cachim P. In: Woodhead Publishing Series in Civil and Structural Engineering. Woodhead Publishing, Waste and Supplementary Cementitious Materials in Concrete, pp 361415. https://doi.org/10.1016/B978-0-08-102156-9.00012-2

25. Dai J, Wang Q, Xie C, Xue Y, Duan Y, Cui X (2019) The effect of fineness on the hydration activity index of ground granulated blast furnace slag. Materials 12(18):2984. https://doi.org/10.3390/ma12182984

26. Ríos JD, Vahí A, Leiva C, la Concha AM-D, Cifuentes $H$ (2019) Analysis of the utilization of air-cooled blast furnace slag as industrial waste aggregates in self-compacting concrete. Sustainability 11(6):1702. https://doi.org/10.3390/su11061702

27. Kalashnikov VI, Khvastunov VL, Tarakanov OV, Kyashkin VM, Petukhov AV (2015) Activation of inactive dump slag for producing composite mineral-slag binders without clinker. Modern Prob Sci Educ 2(2) (In Russian); https://www.scienceeducation.ru/en/article/view?id=21509 
28. Singla R, Kumar S, Alex TC (2020) Reactivity alteration of granulated blast furnace slag by mechanical activation for high volume usage in Portland Slag Cement. Waste Biomass Valor 11(6):2983-2993. https://doi.org/10.1007/s12649-019-00580-6

29. Angulo-Ramírez DE, Valencia-Saavedra WG, Mejía de Gutiérrez R (2020) Alkali-activated concretes based on fly ash and blast furnace slag: compressive strength, water absorption and chloride permeability. Ingeniería e Investigación 40(2): 72-80. https://doi.org/10.15446/ing.investig.v40n2.83893

30. Belkin AS, Tseytlin MA, Zuev GP, Tkachev EB, Shelomkov VS, Murat SG, Sitnov AG, Morzhov VG (1999) Method of processing of slag-graphite-metal wastes of metallurgical production and device for its embodiment. Patent RU2139358C1.1999-10-10. https://patentimages.storage.googleapis.com/9c/28/d0/08324147416db2/RU2139358C1.pdf.

31. Nicks LJ, Nehl FH, Chambers MF (1995) Recovering flake graphite from steelmaking Kish. JOM 47(6):48-51. https://doi. org/10.1007/BF03221205

32. Li J, Liu R, Ma L, Wei L, Cao L, Shen W, Kang F, Huang Z-H (2021) Combining multiple methods for recycling of Kish graphite from steelmaking slags and oil sorption performance of Kish-based expanded graphite. ACS Omega 6(14): 9868-9875. https://doi.org/10.1021/acsomega.1c00591

33. Pronina N, Krüger S, Bornhöft H, Deubener J, Ehrenberg A (2018) Cooling history of a wet-granulated blast furnace slag (GBS). J Non-Crystalline Solids 499:344-349. https://doi.org/10.1016/j.jnoncrysol.2018.07.054

34. Ehrenberg A, Romero Sarcos N, Hart D, Bornhöft H, Deubener J (2020) Influence of the thermal history of granulated blast furnace slags on their latent hydraulic reactivity in cementitious systems. J. Sustain. Metall. 6(2):207-215. https://doi. org/10.1007/s40831-020-00269-4

35. Sakhvadze G, Jandieri G, Sakhvadze D (2020) Method for metallic powder preparation and device for implementation thereof. Patent GE 20207078 B. B 22 F 9/08. Official Bulletin of the Industrial Property of Georgia, №5, 2020.03.10

36. Sakhvadze D, Jandieri G, Bolqvadze I, Shteinberg A, Tsirekidze T (2017) Morphological and metallographic analysis of metallic powders produced by the method of hydro-vacuum dispersion of melts. XIV International Symposium SHS2017, Tbilisi, pp 218-221

37. Jandieri GV, Gorbenko IF, Sakhvadze DV, Tsirekidze TI (2018) Innovative hydrovacuum technology of granulation of metal melts. Sovremennaya Elektrometallurgiya 4(4):70-74 (In Russian). https://doi.org/10.15407/sem2018.04.06

38. Sakhvadze D, Jandieri G, Bolkvadze J (2018) Novel technology of metal powders production by hydrovacuum dispersion of melts. Machines Technol Mater 12(6):236-239 https://stumejournals.com/journals/mtm/2018/6/236

39. Tursunova GR, Atabaev FB, Kakurina LM, Tursunov ZR (2020) On the hydraulic activity of additives for cement of natural and man-made origin. Universum Chem Biol 12(78) https://7universum.com/ru/nature/archive/item/11019

40. GOST 22688-2018. Lime for building purposes. Test methods. Interstate Council for Standardization. Metrology and Certification (ISC)::11. 2019-01-05. https://www.gostinfo.ru/catalog/Details/?id=6432418.

41. Khobotova EB, Ignatenko MI, Kalyuzhnaya YS, Graivoronskaya IV, Larin VI (2020) Toxic properties and hydraulic activity of dump blast furnace slag. Izvestiya. Ferrous Metallurgy 63(9):693-698 (in Russian). https://doi.org/10.17073/0368-0797-2020-9-693-698

42. Dzhandieri GV (2005) Ways of improving the efficiency of the production of cast iron and ferroalloys in blast furnaces and electric furnaces. Metallurgist 49(1-2):7-10. https://doi.org/10.1007/s11015-005-0041-y

\section{Publisher's Note}

Springer Nature remains neutral with regard to jurisdictional claims in published maps and institutional affiliations.

\section{Submit your manuscript to a SpringerOpen ${ }^{\circ}$ journal and benefit from:}

- Convenient online submission

- Rigorous peer review

- Open access: articles freely available online

- High visibility within the field

- Retaining the copyright to your article

Submit your next manuscript at $\mathbf{s p r i n g e r o p e n . c o m ~}$ 